\title{
Analysis of clinical and dosimetric factors associated with severe acute radiation pneumonitis in patients with locally advanced non-small cell lung cancer treated with concurrent chemotherapy and intensity-modulated radiotherapy
}

Anhui Shi, Guangying Zhu*, Hao Wu, Rong Yu, Fuhai Li and Bo Xu

\begin{abstract}
Background: To evaluate the association between the clinical, dosimetric factors and severe acute radiation pneumonitis (SARP) in patients with locally advanced non-small cell lung cancer (LANSCLC) treated with concurrent chemotherapy and intensity-modulated radiotherapy (IMRT).

Methods: We analyzed 94 LANSCLC patients treated with concurrent chemotherapy and IMRT between May 2005 and September 2006. SARP was defined as greater than or equal 3 side effects and graded according to Common Terminology Criteria for Adverse Events (CTCAE) version 3.0.

The clinical and dosimetric factors were analyzed. Univariate and multivariate logistic regression analyses were performed to evaluate the relationship between clinical, dosimetric factors and SARP.

Results: Median follow-up was 10.5 months (range 6.5-24). Of 94 patients, 11 (11.7\%) developed SARP. Univariate analyses showed that the normal tissue complication probability (NTCP), mean lung dose (MLD), relative volumes of lung receiving more than a threshold dose of 5-60 Gy at increments of 5 Gy (V5-V60), chronic obstructive pulmonary disease (COPD) and Forced Expiratory Volume in the first second (FEV1) were associated with SARP $(p<0.05)$. In multivariate analysis, NTCP value $(p=0.001)$ and $\mathrm{V} 10(p=0.015)$ were the most significant factors associated with SARP. The incidences of SARP in the group with NTCP $>4.2 \%$ and NTCP $\leq 4.2 \%$ were $43.5 \%$ and $1.4 \%$, respectively $(p<0.01)$. The incidences of SARP in the group with $\mathrm{V} 10 \leq 50 \%$ and $\mathrm{V} 10>50 \%$ were $5.7 \%$ and $29.2 \%$, respectively $(p<0.01)$.

Conclusions: NTCP value and V10 are the useful indicators for predicting SARP in NSCLC patients treated with concurrent chemotherapy and IMRT.
\end{abstract}

\section{Background}

Lung cancer is the leading cause of cancer-related death in the urban areas of China, accounting for approximately 600,000 deaths per year [1]. Radiotherapy plays an important role in the treatment of lung cancer, especially in

\footnotetext{
* Correspondence: zgypu@yahoo.com.cn

1 Department of Radiation Oncology, Key Laboratory of Carcinogenesis and Translational Research (Ministry of Education), Peking University School of Oncology, Beijing Cancer Hospital \& Institute, Beijing 100142, China Full list of author information is available at the end of the article
}

patients with unresectable tumors. Recent studies have shown that concurrent chemoradiotherapy (CCRT) produced better survival rates than the sequential administration of these two modalities [2-4]. Concurrent chemoradiotherapy has become a standard method for the management of unresectable locally advanced nonsmall cell lung cancer (NSCLC). Unfortunately, the longer survival is achieved at the price of greater toxicity of the lung and the esophageal mucosa [3-5]. 
Radiation pneumonitis is one of the most common dose-limiting toxicities in lung cancer patients receiving CCRT. Severe radiation pneumonitis is life-threatening $[5,6]$. Many studies showed that dose and volume of radiation to lung are associated with the risk of radiation pneumonitis, such as mean lung dose (MLD) [7-11], normal tissue complication probability (NTCP) $[8,12,13]$ value and relative volume of lung receiving more than a threshold dose $\left(\mathrm{V}_{\text {dose }}\right)$ [7,10,14-19]. Technology such as intensity-modulated radiotherapy (IMRT) that could reduce the dose and volume of radiation to lung would potentially decrease the risk of severe radiation pneumonitis, as demonstrated in a planning study by Musherd [20] et al. Further more, Yom et al reported that IMRT was associated with a significantly reduced radiation pneumonitis rate in NSCLC patients treated with concurrent chemotherapy and so far, this is the only study that looked at concurrent chemotherapy and IMRT [21]. More clinical evidence on using IMRT in treating lung cancer is needed.

We started using IMRT to treat lung cancer in 2005, and we evaluated clinical and dosimetric factors associated with severe acute radiation pneumonitis (SARP) in 94 patients with a diagnosis of locally advanced NSCLC treated with concurrent chemotherapy and IMRT. The results are reported here.

\section{Methods}

\section{Patients}

Between May 2005 and September 2006, 94 consecutive locally advanced NSCLC patients were treated with concurrent chemotherapy and IMRT in the Department of Radiation Oncology at the Peking University School of Oncology, Beijing Cancer Hospital \& Institute. Patients were included if they had pathologically confirmed NSCLC and clinically staged as IIIa or IIIb (AJCC 2002), treated with concurrent chemoradiotherapy. Patients were excluded if they received amifostine during concurrent chemotherapy and IMRT.

\section{Treatment planning}

Patients were positioned in the treatment position (generally supine with arms above their heads) and immobilized by using a patient fixation device (Pelvicast Base Plate, 35781-N1, Orfit industries) to improve the setup reproducibility during $\mathrm{CT}$ simulation and delivery of treatment. Treatment-planning CT scan was performed using intravenous contrast if the patient was not allergic to contrast agent. CT scans with slices $5 \mathrm{~mm}$ thick were obtained from the mandible to the lower edge of the liver. The CT image data were directly transferred to the IMRT planning system (Varian Eclipse Treatment Planning Systems 7.0). Radiotherapy targets were defined according to the International Commission on Radiation Units and
Measurements Report Nos. 50 and 62 [22,23], and the internal target volume (ITV), which was used if the required margin for target motion was visualized using fluoroscopy, was defined as a three dimensional (3D) expansion of the $\mathrm{CTV}_{\text {primary }}$ to account for target motion, according to tumor motion. All patients' IMRT treatment plans were designed on Varian Eclipse Treatment Planning Systems to deliver the prescribed dose (1.8-2.0 Gy once per day, $60 \mathrm{~Gy} / 30$ fraction/ 6 weeks or $63 \mathrm{~Gy} / 35$ fractoin/7 weeks) to $95 \%$ of the planning target volume. Five to seven fields were usually used in the treatment plan. Heterogeneity correction with Eclipse-modified Batho method was applied to all dose calculations. Lung dosevolume histograms $(\mathrm{DVH})$ were computed from the 3D dose distributions. Dose limitation for OAR was defined as follows: the V20 of lung less than $31 \%$, the V55 of esophagus less than $50 \%$, the V 40 of heart less than $40 \mathrm{~Gy}$, and the maximum dose administered to the spinal cord was $40 \mathrm{~Gy}$. The concurrent chemotherapy consisted of two courses of Cisplatin-based chemotherapy regimen, 49 patients in all, and Paclitaxel regimen, 45 patients in all.

\section{Evaluation of SARP}

Patients were generally evaluated by their radiation oncologist weekly during concurrent chemoradiotherapy, 3-4 weeks after completion of treatment, every 3 months in the first two years and 6 month intervals during years three to five and once a year thereafter. Chest X-ray or CT scan was performed at each follow-up after completion of chemoradiotherapy. If patients had symptoms, such as fever, cough or shortness of breath, they would be required to have an immediate examination or intervention. A diagnosis of SARP was made with consensus by at least two of three radiation oncologists and was based on clinical symptoms and radiographic infiltrate changes corresponding to the radiation portal observed during concurrent chemoradiotherapy, within the first 6 months after treatment and in the absence of any other likely cause. SARP was defined as greater than or equal to grade 3 side effects (symptomatic, interfering with activities of daily living, $\mathrm{O}_{2}$ indicated) and graded according to Common Terminology Criteria for Adverse Events (CTCAE) version 3.0. [24].

\section{Dosimetric parameters/NTCP models}

The total normal lung volume was defined as the total lung volume minus the primary GTV and volume of the trachea and main bronchi. From each lung DVH, the following dosimetric factors were extracted: $V_{\text {dose }}$ MLD, and NTCP, as derived from the Lyman and Kutcher models. The $\mathrm{V}_{\text {dose }}$ was defined as the percentage of total normal lung volume receiving more than a threshold dose $\mathrm{D}$ of radiation $\left(V_{d}\right)$, where values of $D$ considered were 5-60 
Gy in increments of $5 \mathrm{~Gy}$. The MLD was calculated as the average dose to total normal lung volume [25]. For the NTCP calculations, the Lyman empiric model was used with the following parameters [9]: TD50 $=30.5 \mathrm{~Gy}, \mathrm{~m}=$ 0.3 , and $\mathrm{n}=1$.

\section{Statistical analysis}

We evaluated clinical and dosimetric factors associated with SARP in patients after concurrent chemoradiotherapy. The following clinical parameters were considered: gender, age, smoking and diabetes history, history of COPD, induction chemotherapy, concurrent chemotherapy regimens, performance status and forced expiratory volume in 1 second (FEV1). Dosimetric factors including MLD, V5-V60 and NTCP values were analysed. DVH data and NTCP values were collected for both lungs considered as a parallel organ, Pearson Chi-Square test was performed to compare clinical parameters between patients who developed SARP and those who did not. Univariate and multivariate logistic regression analyses were performed to evaluate data for association between clinical and dosimetric factors and SARP. All statistical tests were 2 -sided and $\mathrm{p} \leq 0.05$ was considered statistically significant.

\section{Results}

All patients were followed up more than 6 months. The median follow-up for all patients was 10.5 months (range, 6.5-24.0 months). Of the 94 patients, 11 (11.7\%) develop SARP; 6 (6.4\%), grade 3; 2(2.1\%), grade 4; and $3(3.2 \%)$ grade 5 . The SARP occurred between 4 week and 12 week (median, 8 week) from commencement of radiation treatment. There was no significant difference in the distribution of clinical parameters between the two groups of patients who developed SARP and those who did not. However, COPD and FEV1 were significant associated with SARP $(p<0.05)$ (Table 1$)$

In univariate analysis, NTCP, MLD and V5-V60 were associated with SARP $(p<0.05)$, and were summarized in Table 2. In multivariate analysis, NTCP $(p=0.001)$ and V10 $(p=0.015)$ were the most significant factors associated with SARP (Table 3). Table 4 shows the association between the dosimetric Parameters (NTCP/V10) and the incidence of SARP for 94 patients; the incidences of SARP in the group with NTCP $>4.2 \%$ and NTCP $\leq 4.2 \%$ were $43.5 \%$ and $1.4 \%$, respectively $(p<0.01)$; the incidences of SARP in the group with V10 $\leq 50 \%$ and V10 $>50 \%$ were $5.7 \%$ and $29.2 \%$, respectively $(p<0.01)$.

\section{Discussion}

To the best of our knowledge, this is the first study to evaluate clinical, dosimetric factors to predicate the risk for developing SARP in locally advanced NSCLC patients during or after concurrent chemotherapy and IMRT in
Chinese population. The univariate and multivariate logistic regression analysis results suggest that NTCP and V10 were the most significant factors associated with SARP $(p<0.05)$.

Radiation pneumonitis takes place usually within 1-6 months after completion of radiation therapy [11], but it can occur as late as 14 months after radiation in few patients [19]. The clinical symptoms of radiation pneumonitis can lead to a poor quality of life for lung cancer patients. Severe radiation pneumonitis after CCRT can be life-threatening if patients are not responsive to treatment. The reported incidences of radiation pneumonitis were inconsistent because of inconsistencies in the criteria used to define radiation pneumonitis, heterogeneity in patient populations, and differences in treatment regimens and radiotherapy techniques [7,11,15,19,26-28]. The incidence of SARP is $11.7 \%$ (11/94) in our study, which was similar to that reported by Yom [21] with IMRT, less than the other results with conventional or conformal radiotherapy $[15,19]$. Perhaps this is because we applied IMRT techniques, which had high conformity and spared more normal lung from irradiation, and therefore may have induced a low rate of severe radiation pneumonitis. The diagnosis of radiation pneumonitis is established by a history of radiotherapy, radiographic evidence (ground-glass opacity, or consolidation changes within the radiation field), and clinical symptoms (dry or productive cough, fever, chest pain, and shortness of breath). The treatment for radiation pneumonitis largely includes oral or intravenous steroids, oxygen, antibiotics and sometimes, assisted ventilation.

At present, there are no generally accepted means to predict the individual patient's risk of developing radiation pneumonitis morbidity accurately even though many clinical and dosimetric assessment of radiation pneumonitis have been studied extensively [7-19]. However, these studies lacked IMRT dosimetry data. In our study, the patient population is quite homogeneous compared with most published studies: $100 \%$ of the patients had Stage III NSCLC, $100 \%$ of the patients are Han people, and $100 \%$ received concurrent chemotherapy and IMRT. The homogeneity of demographic data in the study allowed us to focus on radiation dosimetric factors.

There are many reported studies [7,26,27,29-31] in which the risks of radiation pneumonitis were found to be associated with a variety of clinical parameters (see Additional file 1). Sex, age, smoking history, pre-existing pulmonary disease, performance score and pulmonary function before radiotherapy have been reported to affect the risk for radiation pneumonitis [7,26,29-31]. It also has been reported [27,31] that chemotherapy, particularly when combined with thoracic radiation therapy, was associated with an increased risk for radiation pneumonitis. However, (I) in our study, we only found that COPD 
Table 1: Distribution of the clinical, treatment factors and their association with SARP for 94 patients

\begin{tabular}{|c|c|c|c|}
\hline Characteristic & No. of patients & No. of RP(grade $\geq 3$ ) & p value* \\
\hline \multicolumn{4}{|l|}{ Gender } \\
\hline Male & 73 & 10 & 0.461 \\
\hline Female & 21 & 1 & \\
\hline \multicolumn{4}{|l|}{ Age } \\
\hline$>60$ & 53 & 8 & 0.401 \\
\hline$\leq 60$ & 41 & 3 & \\
\hline \multicolumn{4}{|l|}{ smoking history } \\
\hline Yes & 47 & 6 & 0.748 \\
\hline No & 47 & 5 & \\
\hline \multicolumn{4}{|l|}{ diabetes history } \\
\hline Yes & 13 & 2 & 0.656 \\
\hline No & 81 & 9 & \\
\hline \multicolumn{4}{|c|}{$\begin{array}{l}\text { chronic obstructive } \\
\text { pulmonary disease }\end{array}$} \\
\hline Yes & 11 & 4 & 0.027 \\
\hline No & 83 & 7 & \\
\hline \multicolumn{4}{|c|}{ induction chemotherapy } \\
\hline Yes & 73 & 10 & 0.461 \\
\hline No & 21 & 1 & \\
\hline \multicolumn{4}{|c|}{ concurrent chemotherapy } \\
\hline NVB/DDP & 28 & 3 & 0.643 \\
\hline TXT/DDP & 21 & 2 & \\
\hline PTX & 45 & 6 & \\
\hline \multicolumn{4}{|c|}{ Karnofsky performance status } \\
\hline$\geq 70$ & 80 & 7 & 0.093 \\
\hline$<70$ & 14 & 4 & \\
\hline \multicolumn{4}{|l|}{$\operatorname{Fev1}(\mathrm{L}) * *$} \\
\hline$\geq 2.02$ & 71 & 5 & \\
\hline$<2.02$ & 23 & 6 & 0.036 \\
\hline
\end{tabular}

Abbreviation: * Comparison of clinical factors between patients who developed severe acute radiation pneumonitis and those who did not.

** forced expiratory volume in 1 second. SARP = severe acute radiation pneumonitis

and FEV1 were significantly associated with SARP $(p<$ $0.05)$, suggesting that the pulmonary function before radiotherapy and base-line pulmonary disease is critical for patients' well being after chemoradiotherapy. Our findings are consistent with that of Robnett $\mathrm{TJ}$ [26] and Rancati T [31]. The incidences of SARP in the group with FEV1 $>2.02 \mathrm{~L}$ and FEV1 < 2.02L were $7.04 \%$ and $26.09 \%$, respectively $(p=0.036)$. In addition, univariate analyses show that there is not significant difference statistically between the clinical parameters (sex, age, smoking and diabetes history, induction chemotherapy, concurrent chemotherapy regimens and PS) of patients with and without SARP.
Several reports $[7,9,11,14,15,19]$ showed that some dosimetric factors are likely to influence the risk of radiation pneumonitis (see Additional file 2), such as MLD, NTCP and percentage volume of lung receiving more than a threshold dose (Vdose). Hernando [7] reported 201 lung cancer patients treated with 3D conformal radiotherapy, and the rate of radiation pneumonitis (all grades) was significantly correlated with NTCP, MLD and V30. Kwa [9] retrospectively analyzed 400 lung cancer patients and found MLD was significantly correlated with radiation pneumonitis (grades $\geq 2$ ). Kim [11] reported a study in which 76 lung cancer patients were treated with $3 \mathrm{D}$ conformal radiation therapy. In that study, the rate of 
Table 2: Univariate analysis of the dosimetric parameters(MLD, NTCP, V5-V60) for predicting development of SARP for 94 patients

\begin{tabular}{lllll}
\hline Variable & Median(range) & No RP(n = 83) & RP(n = 11) & pvalue* \\
\hline MLD & $11.59(6.53-18.11) \mathrm{Gy}$ & $\bar{x}=11.26, \mathrm{SD}=2.81$ & $\bar{x}=14.91, \mathrm{SD}=2.91$ & 0.001 \\
NTCP & $2.33 \%(0.51-9.68 \%)$ & $\bar{x}=2.51, \mathrm{SD}=1.73$ & $\bar{x}=5.94, \mathrm{SD}=2.40$ & 0.001 \\
V5 & $58.73 \%(32.89-97.65 \%)$ & $\bar{x}=58.43, \mathrm{SD}=16.57$ & $\bar{x}=69.23, \mathrm{SD}=12.47$ & 0.006 \\
V10 & $42.16 \%(25.28-83.34 \%)$ & $\bar{x}=41.13, \mathrm{SD}=12.69$ & $\bar{x}=52.42, \mathrm{SD}=11.05$ & 0.001 \\
V15 & $29.53 \%(16.46-58.51 \%)$ & $\bar{x}=28.94, \mathrm{SD}=9.12$ & $\bar{x}=38.30, \mathrm{SD}=7.65$ & 0.005 \\
V20 & $18.15 \%(9.46-31.08 \%)$ & $\bar{x}=18.59, \mathrm{SD}=6.03$ & $\bar{x}=28.02, \mathrm{SD}=7.09$ & 0.002 \\
V25 & $12.96 \%(5.90-26.26 \%)$ & $\bar{x}=12.88, \mathrm{SD}=4.42$ & $\bar{x}=20.91, \mathrm{SD}=6.98$ & 0.001 \\
V30 & $10.00 \%(4.68-21.43 \%)$ & $\bar{x}=9.72, \mathrm{SD}=3.45$ & $\bar{x}=15.69, \mathrm{SD}=6.00$ & 0.008 \\
V35 & $9.92 \%(3.89-18.65 \%)$ & $\bar{x}=7.57, \mathrm{SD}=2.86$ & $\bar{x}=11.95, \mathrm{SD}=4.64$ & 0.011 \\
V40 & $8.20 \%(3.29-13.61 \%)$ & $\bar{x}=5.91, \mathrm{SD}=2.48$ & $\bar{x}=9.26, \mathrm{SD}=3.75$ & 0.015 \\
V45 & $7.42 \%(2.73-10.99 \%)$ & $\bar{x}=4.41, \mathrm{SD}=2.25$ & $\bar{x}=6.54, \mathrm{SD}=3.47$ & 0.007 \\
V50 & $7.07 \%(1.94-8.82 \%)$ & $\bar{x}=3.15, \mathrm{SD}=1.94$ & $\bar{x}=4.89, \mathrm{SD}=2.15$ & 0.007 \\
V55 & $6.75 \%(1.33-6.32 \%)$ & $\bar{x}=2.03, \mathrm{SD}=1.65$ & $\bar{x}=3.19, \mathrm{SD}=1.75$ & 0.033 \\
V60 & $5.76 \%(0.80-4.20 \%)$ & $\bar{x}=1.23, \mathrm{SD}=1.09$ & $\bar{x}=1.66, \mathrm{SD}=1.15$ & 0.039
\end{tabular}

Abbreviation: $\mathrm{MLD}=$ mean lung dose; NTCP = normal tissue complication probability; SARP = severe acute radiation pneumonitis; ${ }^{*}$ Comparison of dosimetric factors between patients who developed severe acute RP and those who did not

severe radiation pneumonitis (grades $\geq 3$ ) was significantly correlated with percentage of lung volume receiving 20 Gy (V20) or 30 Gy (V30), with NTCP and MLD. SARP occurred in $45 \%$ and $37 \%$ of patients with MLD of more than 15 Gy and NTCP of $50 \%$ or more, respectively, whereas it occurred in $0 \%$ of patients with a MLD of 10 Gy or less and NTCP of less than 17\%, respectively. In our study, we found the NTCP and MLD were significantly associated with the incidence of SARP. SARP occurred in $2.8 \%$ of patients in whom MLD was less than 14.1 Gy, whereas it occurred in $40.9 \%$ of patients in whom MLD was greater than $14.1 \mathrm{~Gy}$. This is similarly to the other study $[7,9,11]$. In addition, the V5-V60, in increments of 5 Gy, were all found to be significantly associated with the incidence of SARP (see Additional file 2). These findings are consistent with many other published results reported by Wang et al. [19] (rV5-V65), Willner et al. [32] (V10, V20, V30, and V40) or Fay et al. [33] (V30, V40, and $\mathrm{V} 50)$ to be significantly associated with the incidence of radiation pneumonitis.

In our study, although the univariate analyses show that NTCP, MLD, V5-V60, COPD and FEV1 were associated with SARP $(p<0.05)$ however in multivariate analysis, only NTCP ( $=0.001)$ and V10 ( $\mathrm{p}=0.015)$ were found to be the significant factors associated with SARP statisti- cally; the incidences of SARP in the group with NTCP > $4.2 \%$ and NTCP $\leq 4.2 \%$ were $43.5 \%$ and $1.4 \%$, respectively $(\mathrm{p}<0.01)$. The incidences of SARP in the group with V10 $\leq 50 \%$ and $\mathrm{V} 10>50 \%$ were $5.7 \%$ and $29.2 \%$, respectively (p $<0.01$ ). While NTCP can predict the incidence of radiation pneumonitis as confirmed by several studies $[7,11]$, it is inconvenient because of intricate mathematical calculations. However, in practice, V10 was easy to calculate directly from the DVH, and furthermore, the V10 and NTCP are highly correlated $\left(\mathrm{r}_{\mathrm{s}}=0.930, \mathrm{p}=0.001\right)$. V10, rather than V20, as an indicator suggests that radiation damage to the lung during or after IMRT is correlated with volume more closely than that of conventional or conformal radiotherapy. This finding is coincident to results reported recently by Wang et al [19], Zhu [34] and Schallenkamp [35]. Wang et al reported that V5 was the only significant factor associated with treatment-related pneumonitis; the 1-year actuarial incidences of SARP in the group with V $5<42 \%$ and V5 $>42 \%$ were $3 \%$ and $38 \%$, respectively $(\mathrm{p}=0.001)$. Schallenkamp suggested V10 and $\mathrm{V} 13$ to be the predictors of radiation pneumonitis risk. The incidences of Grade $\geq 2$ pneumonitis in the patients with $\mathrm{V} 10 \leq 32 \% 32 \%-43 \%$ and $\mathrm{V} 10>43 \%$ were $0 \%-9 \%$, $10 \%-20 \%$ and $>20 \%$, respectively $(\mathrm{p}<0.01)$. This finding is further confirmed by Yorke et al [10] and Gopal et al [36]. 
Table 3: Multivariate analysis of the dosimetric and clinical factors associated with SARP for 94 patients

\begin{tabular}{llll}
\hline Varibale & OR & $\mathbf{9 5 \% C l}$ & $\boldsymbol{p}$ value* \\
\hline NTCP & 10.411 & $1.835-56.024$ & 0.008 \\
MLD & 3.199 & $0.196-52.380$ & 0.415 \\
V5 & 4.024 & $0.765-21.163$ & 0.100 \\
V10 & 9.023 & $1.910-42.625$ & 0.005 \\
V15 & 4.024 & $0.765-21.163$ & 0.100 \\
V20 & 2.801 & $0.834-9.403$ & 0.096 \\
V25 & 3.423 & $0.713-16.421$ & 0.124 \\
V30 & 2.613 & $0.759-8.995$ & 0.128 \\
V35 & 2.313 & $0.751-7.122$ & 0.144 \\
V40 & $0.292-21.152$ & 0.405 \\
V45 & 2.485 & $0.373-14.146$ & 0.475 \\
V50 & 1.219 & $0.229-22.824$ & 0.318 \\
V55 & 1.613 & $0.215-20.061$ & 0.594 \\
V60 & 1.446 & $0.070-18.612$ & 0.527 \\
COPD & 1.139 & $0.008-3.159$ & 0.225 \\
FEV1 & 0.154 & $0.010-1.346$ & 0.085
\end{tabular}

Abbreviation: $\mathrm{MLD}=$ mean lung dose; $\mathrm{NTCP}=$ normal tissue complication probability; $\mathrm{SARP}=$ severe acute radiation pneumonitis; ${ }^{*}$ Univariate logistic regression analysis; $\mathrm{COPD}=$ chronic obstructive pulmonary disease; $\mathrm{FEV} 1=$ forced expiratory volume in 1 second; $\mathrm{OR}=$ the value of odds ratio; $95 \% \mathrm{Cl}=$ confidence interval

Yorke [10] reported that the incidence of radiation pneumonitis rose quickly when the MLD was higher than 10 Gy. Gopal et al [36] found a sharp loss in the diffusing capacity for carbon monoxide of normal lung exposed to 13 Gy or higher, and suggested that a small dose of radiation to a large volume of lung could be much worse than a large dose to a small volume in functional lung damage. So we think that the lung received a small dose of radiation as low as $10 \mathrm{~Gy}$ to a large volume is not safe. In contrast, Willner [32] et al. reported that the logistic regression curve for V10, V20, V30, and V40 showed an increasing steepness toward higher doses and an increase in steepness from V10 to V40 was more pronounced for the total lung; A 10\% increase in V10 resulted in a 10\% increase in pneumonitis rate, whereas a $10 \%$ increase in
V40 resulted in a $20 \%$ increase in pneumonitis rate. So the investigators concluded that a small dose, such as 10 Gy, to a large volume of normal lung is preferable to a large dose, such as $40 \mathrm{~Gy}$, to a small volume. However, we believe that the volume of normal lung receiving lowdose irradiation should be minimized to avoid SARP. We recommend to keep the value of V10 below $50 \%$, so as to keep the incidence of SARP lower than $5.7 \%$.

In conclusion, NTCP and V10 are useful indicators of risk for development of SARP in locally advanced NSCLC patients after concurrent chemotherapy and IMRT. Thoracic concurrent chemoradiotherapy should be planned with caution when the volume of normal lung receiving 10 Gy or more is large with IMRT.

Table 4: Observed rates of SARP as a function of dosimetric parameters (NTCP/V10)

\begin{tabular}{llllll}
\hline Varibale & Median(Range) & Group & No. of patients & No. of RP & $p$ value* \\
\hline NTCP & $2.33 \%$ & $\leq 4.20 \%$ & 71 & $1(1.4 \%)$ & 0.001 \\
& $(0.51-9.68 \%)$ & $>4.20 \%$ & 23 & $10(43.5 \%)$ & $4(5.7 \%)$ \\
V10 & $42.16 \%$ & $\leq 50 \%$ & 70 & $7(29.2 \%)$ & 0.005 \\
& $(9.91-83.34 \%)$ & $>50 \%$ & 24 & \\
\hline
\end{tabular}

Abbreviation: $\mathrm{NTCP}=$ normal tissue complication probability; SARP = severe acute radiation pneumonitis; ${ }^{*}$ Multivariate logistic regression analysis. 


\section{Additional material}

Additional file 1 Clinical parameters predictive of risk of RP as reported in the literature. The file contains a number of important clinical parameters predictive of risk of RP as reported in the literature.

Additional file 2 Dosimetric parameters predictive of risk of RP as reported in the literature. The file contains a number of important dosimetric parameters predictive of risk of RP as reported in the literature.

\section{Competing interests}

The authors declare that they have no competing interests in this study.

\section{Authors' contributions}

GZ and AS participated in the design of the study and performed the statistical analysis and drafted the manuscript. HW, RY, FL and BX participated in acquisition of data. All authors read and approved the final manuscript.

\section{Acknowledgements}

The study was funded by National Natural Science Foundation of China (30870738).

We thank Drs. Zhongxing Liao and Joe Y. Chang of the University of Texas M. D. Anderson Cancer Center of Texas, USA for reviewing the manuscript.

\section{Author Details}

Department of Radiation Oncology, Key Laboratory of Carcinogenesis and Translational Research (Ministry of Education), Peking University School of Oncology, Beijing Cancer Hospital \& Institute, Beijing 100142, China

Received: 30 January 2010 Accepted: 12 May 2010

Published: 12 May 2010

\section{References}

1. Liandi Li, Keqin Yao, Siwei Zhang, Fengzhu Lu, Xiaonong Zou: Statistical Analysis of Data from 12 Cancer Registries in China. Bull Chin Cancer 2002, 11:497-507.

2. Furuse K, Fukuoka M, Kawahara M, Nishikawa H, Takada Y, Kudoh S, Katagami N, Ariyoshi Y: Phase III study of concurrent versus sequential thoracic radiotherapy in combination with mitomycin, vindesine, and cisplatin in unresectable stage III non-small-cell lung cancer. J Clin Oncol 1999, 17:2692-2699.

3. Komaki R, Seiferheld W, Curran W, Langer C, Lee J, Hauser S, Movasas B, Wasserman T, Russell A, Byhardt R: Sequential vs. concurrent chemotherapy and radiation therapy for inoperable non-small cell lung cancer (NSCLC): Analysis of failures in a phase III study (RTOG 9410) [Abstract]. Int J Radiat Oncol Biol Phys 2000, 48:113.

4. Curran W, Scott C, Langer C, Komaki R, Lee J, Hauser S, Movsas B, Wasserman T, Sause W, Cox J: Long-term benefit is observed in a phase III comparison of sequential vs concurrent chemo-radiation for patients with unresected stage III Nsclc: RTOG 9410. Am Soc Clin Oncol 2003, 22: abstr 2499

5. Kirkbride $P$, Hatton $M$, Lorigan $P$, Joyce $P$, Fisher $P$ : Fatal pulmonary fibrosis associated with induction chemotherapy with carboplatin and vinorelbine followed by CHART radiotherapy for locally advanced nonsmall cell lung cancer. Clin Oncol 2002, 14:361-366.

6. Semrau S, Bier A, Thierbach U, Virchow C, Ketterer P, Fietkau R: Concurrent radiochemotherapy with vinorelbine plus cisplatin or carboplatin in patients with locally advanced non-small-cell lung cancer (NSCLC) and an increased risk of treatment complications: Preliminary results. Strahlenther Onkol 2003, 179(12):823-831.

7. Hernando ML, Marks LB, Bentel GC, Zhou SM, Hollis D, Das SK, Fan M Munley MT, Shafman TD, Anscher MS, Lind PA: Radiation-induced pulmonary toxicity: A dose-volume histogram analysis in 201 patients with lung cancer. Int J Radiat Oncol Biol Phys 2001, 51:650-659.

8. Graham MV: Predicting radiation response. Int J Radiat Oncol Biol phys 1997, 39:561-562

9. Kwa SL, Lebesque JV, Theuws JC, Marks LB, Munley MT, Bentel G, Oetzel D, Spahn U, Graham MV, Drzymala RE, Purdy JA, Lichter AS, Martel MK, Ten Haken RK: Radiation pneumonitis as a function of mean lung dose: An analysis of pooled data of 540 patients. Int J Radiat Oncol Biol Phys 1998, 42:1-9.
10. Yorke ED, Jackson A, Rosenzweig KE, Merrick SA, Gabrys D, Venkatraman ES, Burman CM, Leibel SA, Ling CC: Dose-volume factors contributing to the incidence of radiation pneumonitis in non-small-cell lung cancer patients treated with three-dimensional conformal radiation therapy. Int J Radiat Oncol Biol Phys 2002, 54:329-339.

11. Kim TH, Cho KH, Pyo HR, Lee JS, Zo Jl, Lee DH, Lee JM, Kim HY, Hwangbo B, Park SY, Kim JY, Shin KH, Kim DY: Dose-volumetric parameters for predicting severe radiation pneumonitis after three-dimensional conformal radiation therapy for lung cancer. Radiology 2005, 235:208-215.

12. Marks LB, Munley MT, Bentel GC, Zhou SM, Hollis D, Scarfone C, Sibley GS, Kong FM, Jirtle R, Jaszczak R, Coleman RE, Tapson V, Anscher M: Physical and biological predictors of changes in whole-lung function following thoracic irradiation. Int J Radiat Oncol Biol Phys 1997, 39:563-570.

13. Armstrong J, Raben A, Zelefsky M, Burt M, Leibel S, Burman C, Kutcher G, Harrison L, Hahn C, Ginsberg R, Rusch V, Kris M, Fuks Z: Promising survival with three-dimensional conformal radiation therapy for non-small cell lung cancer. Radiother Oncol 1997, 44:17-22.

14. Graham MV, Purdy JA, Emami B, Harms W, Bosch W, Lockett MA, Perez CA: Clinical dose-volume histogram analysis for pneumonitis after 3D treatment for non-small cell lung cancer (NSCLC). Int J Radiat Oncol Biol Phys 1999, 45:323-329.

15. Tsujino K, Hirota S, Endo M, Obayashi K, Kotani Y, Satouchi M, Kado T, Takada Y: Predictive value of dose-volume histogram parameters for predicting radiation pneumonitis after concurrent chemoradiation for lung cancer. Int J Radiat Oncol Biol Phys 2003, 55:110-115.

16. Chang DT, Olivier KR, Morris CG, Liu C, Dempsey JF, Benda RK, Palta JR: The impact of heterogeneity correction on dosimetric parameters that predict for radiation pneumonitis. Int J Radiat Oncol Biol Phys 2006, 65:125-131

17. Armstrong JG, Zelefsky MJ, Leibel SA, Burman C, Han C, Harrison LB, Kutcher GJ, Fuks ZY: Strategy for dose escalation using 3-dimensional conformal radiation therapy for lung cancer. Ann Oncol 1995, 6:693-697.

18. Marks LB, Spencer DP, Sherouse GW, Bentel G, Clough R, Vann K, Jaszczak $R$, Coleman RE, Prosnitz LR: The role of three dimensional functional lung in radiation treatment planning: the functional dose volume histogram. Int J Radiat Oncol Biol phys 1995, 33:65-75.

19. Wang S, Liao Z, Wei X, Liu HH, Tucker SL, Hu CS, Mohan R, Cox JD, Komaki $R$ : Analysis of clinical and dosimetric factors associated with treatmentrelated pneumonitis (TRP) in patients with non-small-cell lung cancer (NSCLC) treated with concurrent chemotherapy and threedimensional conformal radiotherapy (3-DCRT). Int J Radiat Oncol Biol Phys 2006, 66:1399-1407.

20. Murshed H, Liu HH, Liao Z, Barker JL, Wang X, Tucker SL, Chandra A, Guerrero T, Stevens C, Chang JY, Jeter M, Cox JD, Komaki R, Mohan R: Dose and volume reduction for normal lung using intensitymodulated radiotherapy for advanced-stage non-small-cell lung cancer. Int J Radiat Oncol Biol Phys 2004, 58:1258-1267.

21. Yom SS, Liao Z, Liu HH, Tucker SL, Hu CS, Wei X, Wang X, Wang S, Mohan R, Cox JD, Komaki R: Initial evaluation of treatment-related pneumonitis in advanced-stage non-small-cell lung cancer patients treated with concurrent chemotherapy and intensity-modulated radiotherapy. Int J Radiat Oncol Biol Phys 2007, 68:94-102.

22. International Commission on Radiation Units and Measurements: ICRU Report 50: Prescribing, recording, and reporting photon beam therapy. Bethesda; International Commission on Radiation Units and Measurements; 1993.

23. International Commission on Radiation Units and Measurements: ICRU Report 62: Prescribing, recording, and reporting photon beam therapy (supplement to ICRU Report 50). Bethesda; International Commission on Radiation Units and Measurements; 1999.

24. Trotti A, Colevas AD, Setser A, Rusch V, Jaques D, Budach V, Langer C, Murphy B, Cumberlin R, Coleman CN, Rubin P: CTCAE v3.0: Development of a comprehensive grading system for the adverse effects of cancer treatment. Semin Radiat Oncol 2003, 13:176-181.

25. Kwa SL, Theuws JC, Wagenaar A, Damen EM, Boersma LJ, Baas P, Muller $\mathrm{SH}$, Lebesque JV: Evaluation of two dose-volume histogram reduction models for the prediction of radiation pneumonitis. Radiother Oncol 1998, 48:61-69.

26. Robnett TJ, Machtay M, Vines EF, McKenna MG, Algazy KM, McKenna WG: Factor predicting severe radiation pneumonitis in patients receiving 
definitive chemoradiation for lung cancer. Int $J$ Radiat Oncol Biol Phys 2000, 48:89-94.

27. Yamada M, Kudoh S, Hirata K, Nakajima T, Yoshikawa J: Risk factors of pneumonitis following chemoradiotherapy for lung cancer. Eur $J$ Cancer 1998, 34:71-75.

28. Byhardt RW, Scott C, Sause WT, Emami B, Komaki R, Fisher B, Lee JS, Lawton C: Response, toxicity, failure patterns, and survival in five Radiation Therapy Oncology Group (RTOG) trials of sequential and/or concurrent chemotherapy and radiotherapy for locally advanced nonsmall-cell carcinoma of the lung. Int J Radiat Oncol Biol Phys 1998, 42(3):469-78.

29. Claude L, Pérol D, Ginestet C, Falchero L, Arpin D, Vincent M, Martel I, Hominal S, Cordier JF, Carrie C: A prospective study on radiation pneumonitis following conformal radiation therapy in non-small-cell lung cancer: Clinical and dosimetric factors analysis. Radiother Oncol 2004, 71:175-181.

30. Quon H, Shepherd FA, Payne DG, Coy P, Murray N, Feld R, Pater J, Sadura A, Zee B: The influence of age on the delivery, tolerance, an efficacy of thoracic irradiation in the combined modality treatment of limited stage small cell lung cancer. Int J Radiat Oncol Biol Phys 1999, 43:39-45.

31. Rancati T, Ceresoli GL, Gagliardi G, Schipani S, Cattaneo GM: Factors predicting radiation pneumonitis in lung cancer patients: A retrospective study. Radiother Oncol 2003, 67:275-283.

32. Willner J, Jost A, Baier K, Flentje M: A little to a lot or a lot to a little? An analysis of pneumonitis risk from dose-volume histogram parameters of the lung in patients with lung cancer treated with 3-D conformal radiotherapy. Strahlenther Onkol 2003, 179:548-556.

33. Fay M, Tan A, Fisher R, Mac Manus M, Wirth A, Ball D: Dose-volume histogram analysis as predictor of radiation pneumonitis in primary lung cancer patients treated with radiotherapy. Int J Radiat Oncol Biol Phys 2005, 61:1355-1363.

34. Zhu X, Wang L, Ou G, Wang Y, Zhang H, Chen D, Feng Q, Dai J, Zhang Z, Yin W: Risk Factors for Severe Acute Radiation Pneumonitis In Stage III Non-Small-Cell Lung Cancer Treated With 3D-CRT [Abstract]. Int J Radiat Oncol Biol Phys 2006, 66:S466.

35. Schallenkamp JM, Miller RC, Brinkmann DH, Foote T, Garces YI: Incidence of radiation pneumonitis after thoracic irradiation: dose-volume correlates. Int J Radiat Oncol Biol Phys 2007, 67:410-6.

36. Gopal R, Tucker SL, Komaki R, Liao Z, Forster KM, Stevens C, Kelly JF, Starkschall G: The relationship between local dose and loss of function for irradiated lung. Int J Radiat Oncol Biol Phys 2003, 56:106-113.

doi: $10.1186 / 1748-717 X-5-35$

Cite this article as: Shi et al., Analysis of clinical and dosimetric factors associated with severe acute radiation pneumonitis in patients with locally advanced non-small cell lung cancer treated with concurrent chemotherapy and intensity-modulated radiotherapy Radiation Oncology 2010, 5:35

\section{Submit your next manuscript to BioMed Central} and take full advantage of:

- Convenient online submission

- Thorough peer review

- No space constraints or color figure charges

- Immediate publication on acceptance

- Inclusion in PubMed, CAS, Scopus and Google Scholar

- Research which is freely available for redistribution

Submit your manuscript at www.biomedcentral.com/submit
C Biomed Central 